\title{
Assessment of the Efficacy of Periodontal Tissue Regeneration using Non-resorbable and Bioabsorbable GTR Membrane-A Clinical Comparative Study
}

\author{
Mohammad Jalaluddin ${ }^{1}$, Rajanna KV Patel ${ }^{2}$, Sultan A Almalki ${ }^{3}$, Preethi Nagdev ${ }^{4}$, Rincy Roshan ${ }^{5}$, Roshan R Varkey ${ }^{6}$
}

\begin{abstract}
Aim: The present study aims to assess the efficacy of non-resorbable and bioabsorbable guided tissue regeneration (GTR) membrane periodontal tissue regenerative methods.

Materials and methods: Thirty teeth taken from 20 patients ( 8 males and 12 females) within the age range of 20-55 years having chronic periodontitis were enrolled in this trial. All the enrolled patients underwent phase I therapy which included scaling and root planing performed in two sittings by a single practitioner. Patients who fulfilled the selection criteria entered the study and were randomly allocated to the three groups. Group I: control group, group II: patients who received a non-resorbable GTR membrane, and group III: patients who received a bioabsorbable GTR membrane. The clinical parameters that were documented at baseline, 3 months, and 6 months postoperatively were the gingival index, plaque index, and probing depth (vertical and horizontal) for all the three groups.

Results: The mean gingival index score was $1.64 \pm 0.32$ in group III at baseline, which decreased to $1.20 \pm 0.10$ at 6 months postoperatively. The plaque index reduced from $1.36 \pm 0.46$ at baseline to $1.04 \pm 0.01$ at 6 months postoperatively. The vertical and horizontal probing depths demonstrated a statistically significant difference between all the three groups.

Conclusion: The present study established that both membranes resulted in clinically and statistically significant improvements in the treatment of grade II furcation defects.

Keywords: Bioabsorbable membrane, Grade II furcation defects, Guided tissue regeneration, Non-resorbable membranes.

The Journal of Contemporary Dental Practice (2019): 10.5005/jp-journals-10024-2578
\end{abstract}

\section{INTRODUCTION}

The periodontal treatment aims at effective elimination of periodontopathic organisms, regulation of periodontal infection, cessation of inflammation, and helps to repair the damaged periodontal tissues. All these can be achieved by several regenerative procedures. However, dismissal or treatment of the infection should be the utmost goal, particularly in patients with aggressive periodontitis.

Various regenerative methods that can repair the tissues destroyed by periodontal diseases include bone grafts, enamel matrix derivatives, and the guided tissue regeneration (GTR) membranes. Many animal and human trials that were previously conducted have demonstrated that GTR-based non-resorbable and bioabsorbable barrier membranes can probably restore the

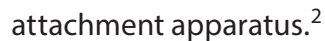

GTR is a powerful surgical technique in which the area around the root surface is mechanically protected with the help of a barrier membrane and permit careful regeneration of the cells of periodontal ligament by pluripotent cells. ${ }^{3}$ Additionally, the membrane helps to turn away the practical mechanical stresses from the tooth and clot interface and permits the organization of the blood clot to proceed in an uninterrupted manner during the initial and the most important period of wound healing. ${ }^{4}$

There have been very few studies ${ }^{5,6}$ that have evaluated the comparative regenerative efficacy of bioabsorbable membranes and graft materials. Hence, the present study was piloted to evaluate the efficacy of non-resorbable and bioabsorbable GTR membranes in periodontal tissue regeneration in teeth having grade II furcation defects.
${ }^{1}$ Department of Periodontics and Oral Implantology, Kalinga Institute of Dental Sciences, KIIT Deemed to be University, Bhubaneswar, Odisha, India

${ }^{2}$ Department of Prosthodontics, Sri Rajiv Gandhi College of Dental Sciences and Hospital, Bengaluru, Karnataka, India

${ }^{3}$ Department of Preventive Dental Sciences, College of Dentistry, Prince Sattam Bin Abdulaziz University, Alkharj, Kingdom of Saudi Arabia

${ }^{4}$ Department of Public Health Dentistry, SJM Dental College and Hospital, Chitradurga, Karnataka, India

5,6 Department of Periodontics, Al-Azhar Dental College, Thodupuzha, Kerala, India

Corresponding Author: Mohammad Jalaluddin, Department of Periodontics and Oral Implantology, Kalinga Institute of Dental Sciences, KIIT Deemed to be University, Bhubaneswar, Odisha, India, Phone: +91 9338131843, e-mail: drjalal1979@gmail.com

How to cite this article: Jalaluddin M, Patel RKV, et al. Assessment of the Efficacy of Periodontal Tissue Regeneration using Non-resorbable and Bioabsorbable GTR Membrane-A Clinical Comparative Study. J Contemp Dent Pract 2019;20(6):675-679.

Source of support: Nil

Conflict of interest: None

\section{Materials and Methods}

Thirty teeth, taken from 20 consented patients ( 8 males and 12 females), aged between 20 years and 55 years, suffering from chronic periodontitis were selected from the Outpatient Department of Periodontics, Kalinga Institute of Dental Sciences, Bhubaneswar, India.

(0) The Author(s). 2019 Open Access This article is distributed under the terms of the Creative Commons Attribution 4.0 International License (https://creativecommons. org/licenses/by-nc/4.0/), which permits unrestricted use, distribution, and non-commercial reproduction in any medium, provided you give appropriate credit to the original author(s) and the source, provide a link to the Creative Commons license, and indicate if changes were made. The Creative Commons Public Domain Dedication waiver (http://creativecommons.org/publicdomain/zero/1.0/) applies to the data made available in this article, unless otherwise stated. 
Patients who had the following conditions were included (1) presence of good overall health and had no contraindication for periodontal surgery, (2) absence of any known allergic reaction to collagen products, (3) maintenance of good plaque control, (4) absence of periodontal surgery since 1 year, and (5) vertical probing depth (VPD) and horizontal probing depth greater than or equal to $4 \mathrm{~mm}$.

The exclusion criteria were as follows: (1) patients with poor oral hygiene, (2) use of cigarettes or any tobacco products, (3) use of antibiotics at least 1 month prior to study, (4) teeth with poor endodontic/restorative treatments or defects extending into furcations and around the third molars, and (5) mobile teeth with $\geq$ grade II mobility.

\section{Initial Therapy}

The enrolled patients underwent phase I therapy which comprised scaling and root planing done in two sittings by a single operator (P6 Piezo electric scaler, BONART ${ }^{\oplus}$, Taiwan R.O.C and GraceyCurrettes, Hu Freidy ${ }^{\circledR}$, Chicago, IL, USA), post which oral hygiene instructions were given. After 4 weeks of phase I therapy, the patients were recalled and evaluated to confirm the criteria for selection (Fig. 1). The patients who fulfilled the selection criteria for the study were randomly allocated to three groups.

\section{Group l: Control Group}

The surgical area was anesthetized with $2 \%$ xylocaine with 1:80,000 adrenaline. A full-thickness mucoperiosteal flap was reflected. The furcation defect was completely debrided and roots were planed. The surgical area was profusely irrigated. The horizontal extent of furcation defect was measured along an imaginary line which is tangential to the root surface to the horizontal component of the defect at baseline. A spatula and dappen dish was used to mix hydroxyapatite bone graft material (G-Graft) with saline. This mixture was packed into the defect to completely fill it (Fig. 2). Later, the flaps were repositioned and sutured back. The surgical site was covered with periodontal dressing (Coe Pak ${ }^{\circledR}$, GC America, Alsip, IL, USA) and left for 7 days.

\section{Group II: Non-resorbable GTR Membrane [density polytetrafluoroethylene (d-PTFE) (Tef Gen-FD)]}

After phase I therapy, 10 patients underwent periodontal flap surgery as described above. After complete debridement of

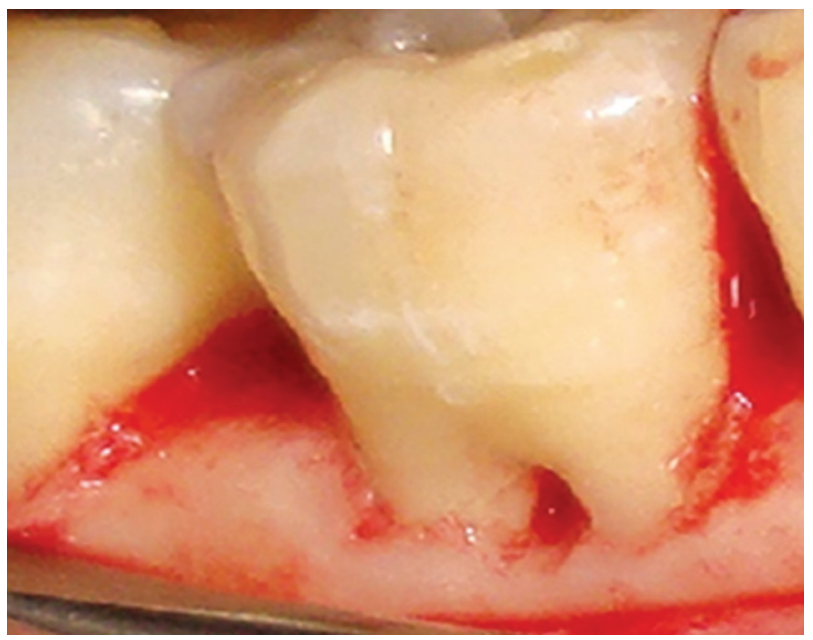

Fig. 1: Grade II furcation defect after initial therapy

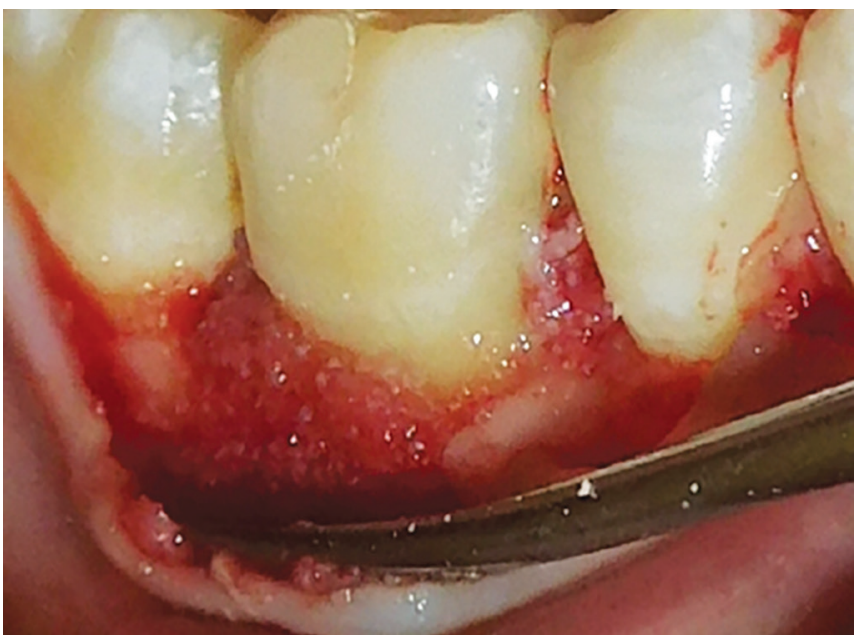

Fig. 2: Placement of bone graft material

furcation defect, the hydroxyapatite bone graft material was condensed and covered with THE non-resorbable GTR membrane [d-PTFE (Tef Gen-FD)]. The flap was positioned back with sutures to stabilize the membrane. Periodontal dressing was applied over the surgical site and allowed to stay for 7 days.

\section{Group III: Bioabsorbable GTR Membrane (Healiguide)}

After phase I therapy, 10 patients underwent periodontal flap surgery as stated above. After thorough debridement of furcation defect, hydroxyapatite bone graft material was condensed and covered with the bioabsorbable GTR membrane (Fig. 3). The flap was positioned back with sutures to stabilize the membrane. Periodontal dressing was applied over the surgical site and allowed to stay for 7 days.

All patients received antibiotics (625 $\mathrm{mg}$ of amoxicillin and clavulanic acid tablet) and analgesics (ibuprofen $400 \mathrm{mg}$ ) for 5 days. The patients were advised to follow strict dietary instructions and perform appropriate plaque control by rinsing with $10 \mathrm{~mL}$ of $0.2 \%$ chlorhexidine gluconate two times a day for 2 weeks, postoperatively. After 1 week of surgery, sutures were removed, and postoperative assessments were done.

The clinical parameters that were documented postoperatively include the gingival index, plaque index, and probing depth

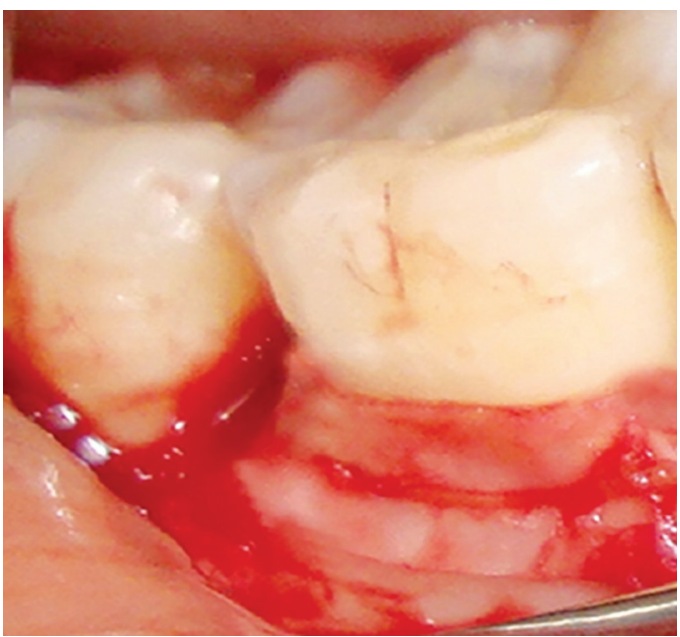

Fig. 3: Placement of bioabsorbable membrane 
(vertical and horizontal), for all the three groups, recorded at baseline, 3 months and 6 months.

\section{Statistical Analysis}

The software that was used for the analysis was Statistical Package for the Social Sciences (SPSS) 20. The mean difference between the different groups was calculated using the analysis of variance (ANOVA) test. The level of significance was set at $5 \%$.

\section{Results}

The comparison of mean values of gingival indexes at baseline, 3 months and 6 months postoperatively is displayed in Table 1. In group I, the mean gingival index score was $1.60 \pm 0.12,1.49 \pm 0.20$, and $1.42 \pm 0.15$, at baseline, after 3 months, and after 6 months, respectively. No statistically significant difference was found between the different time intervals. In group II, the mean gingival index score decreased from $1.58 \pm 0.02$ at baseline to $1.28 \pm 0.10$ at 6 months. Similarly, the mean gingival index score reduced from $1.64 \pm 0.32$ at baseline to $1.20 \pm 0.10$ at 6 months in group III. A statistically significant difference was found at different intervals for both groups II and III.

Table 2 displays the comparison of the mean value of plaque indexes at baseline, 3 months, and 6 months. The mean plaque index score reduced from $1.40 \pm 0.10$ at baseline to $1.18 \pm 0.28$ at 6 months in group I. In group II, the mean plaque index score decreased from $1.39 \pm 0.12$ at baseline to $1.10 \pm 0.10$ at 6 months. In group III, the mean plaque index score reduced from $1.36 \pm 0.46$ at baseline to $1.04 \pm$ 0.01 at 6 months. All the three groups demonstrated statistically significant difference at different intervals.

The mean value for vertical probing depth that was recorded at baseline in group I was $5.10 \pm 0.66$, and this decreased to $3.90 \pm 0.01$ at 6 months. Similarly, the mean values for vertical probing depth

Table 1: Mean value comparison of gingival index at baseline, 3 months and 6 months

\begin{tabular}{llllll}
\hline & Groups & & Mean \pm SD & Fvalue & pvalue \\
\hline Gingival & Group I & Baseline & $1.60 \pm 0.12$ & 8.980 & 0.08 \\
index & & 3 months & $1.49 \pm 0.20$ & & \\
& & 6 months & $1.42 \pm 0.15$ & & \\
& Group II & Baseline & $1.58 \pm 0.02$ & 9.145 & 0.01 \\
& & 3 months & $1.50 \pm 0.14$ & & \\
& 6 months & $1.28 \pm 0.10$ & & \\
& Group III & Baseline & $1.64 \pm 0.32$ & 8.662 & 0.01 \\
& & 3 months & $1.44 \pm 0.20$ & & \\
& & 6 months & $1.20 \pm 0.10$ & & \\
\hline
\end{tabular}

Table 2: Mean value comparison of plaque index at baseline, 3 months and 6 months

\begin{tabular}{|c|c|c|c|c|c|}
\hline & Groups & & Mean \pm SD & $F$ value & $p$ value \\
\hline \multirow{9}{*}{$\begin{array}{l}\text { Plaque } \\
\text { index }\end{array}$} & \multirow[t]{3}{*}{ Group I } & Baseline & $1.40 \pm 0.10$ & \multirow[t]{3}{*}{8.124} & \multirow[t]{3}{*}{0.01} \\
\hline & & 3 months & $1.38 \pm 0.32$ & & \\
\hline & & 6 months & $1.18 \pm 0.28$ & & \\
\hline & \multirow[t]{3}{*}{ Group II } & Baseline & $1.39 \pm 0.12$ & \multirow[t]{3}{*}{8.953} & \multirow[t]{3}{*}{0.01} \\
\hline & & 3 months & $1.22 \pm 0.09$ & & \\
\hline & & 6 months & $1.10 \pm 0.10$ & & \\
\hline & \multirow[t]{3}{*}{ Group III } & Baseline & $1.36 \pm 0.46$ & \multirow[t]{3}{*}{9.176} & \multirow[t]{3}{*}{0.01} \\
\hline & & 3 months & $1.18 \pm 0.46$ & & \\
\hline & & 6 months & $1.04 \pm 0.01$ & & \\
\hline
\end{tabular}

Table 3: Mean value comparison of vertical probing depth at baseline, 3 months and 6 months

\begin{tabular}{llllll}
\hline & Groups & & Mean \pm SD & Fvalue & p value \\
\hline Vertical & Group I & Baseline & $5.10 \pm 0.66$ & 10.560 & 0.001 \\
probing & & 3 months & $4.70 \pm 0.13$ & & \\
depth & & 6 months & $3.90 \pm 0.01$ & & \\
& Group II & Baseline & $5.58 \pm 0.60$ & 11.264 & 0.001 \\
& & 3 months & $4.02 \pm 0.17$ & & \\
& & 6 months & $3.28 \pm 0.11$ & & \\
& Group III & Baseline & $5.64 \pm 0.98$ & 9.017 & 0.001 \\
& & 3 months & $4.10 \pm 0.62$ & & \\
& & 6 months & $2.78 \pm 0.31$ & & \\
\hline
\end{tabular}

Table 4: Mean value comparison of horizontal probing depth at baseline, 3 months and 6 months

\begin{tabular}{llllll}
\hline & Groups & & Mean $\pm S D$ & Fvalue & pvalue \\
\hline Horizontal & Group I & Baseline & $4.80 \pm 0.33$ & 11.120 & 0.001 \\
probing & & 3 months & $3.50 \pm 0.21$ & & \\
depth & & 6 months & $2.55 \pm 0.19$ & & \\
& Group II & Baseline & $4.58 \pm 0.02$ & 10.514 & 0.001 \\
& & 3 months & $3.50 \pm 0.14$ & & \\
& & 6 months & $2.89 \pm 0.16$ & & \\
& Group III & Baseline & $4.74 \pm 0.10$ & 13.088 & 0.001 \\
& & 3 months & $3.01 \pm 0.96$ & & \\
& & 6 months & $2.20 \pm 0.24$ & & \\
\hline
\end{tabular}

decreased from $5.58 \pm 0.60$ to $3.28 \pm 0.11$ and from $5.64 \pm 0.98$ to 2.78 \pm 0.31 , in groups II and III, respectively. The intergroup comparison of probing depths was found to be statistically significant (Table 3 ).

Table 4 shows the mean value for horizontal probing depth recorded in group I at baseline as $4.80 \pm 0.33$ which decreased to $2.55 \pm 0.19$ at 6 months. In group II, the values decreased from $4.58 \pm$ 0.02 to $2.89 \pm 0.16$ and in group III, the values decreased from $4.74 \pm 0.10$ to $2.20 \pm 0.24$. Intergroup comparisons of the horizontal probing depth demonstrated statistically significant difference.

\section{Discussion}

Gingival recession is a characteristic feature not only in people with high levels of oral hygiene, but also seen in patients having poor oral hygiene. Achieving expectable and esthetic coverage of the root surface is an important aspect of periodontal treatment. The root coverage procedure is useful in several other conditions, such as elimination of plaque trap, reduction of root caries, and sensitivity. Over the last few decades, various surgical procedures have been recommended to attain root coverage on uncovered root surfaces. ${ }^{7}$

Recently, it has been demonstrated that regardless of the surgical technique being used, good results can be obtained with root coverage procedures, if the biological conditions that are needed for root coverage are fulfilled (maintenance of interdental soft and hard tissue height). ${ }^{8}$

The periodontal treatment aims to restore the periodontal tissues that are damaged by the disease process via a predictable method. Nevertheless, many conventional periodontal treatments have led to inadequate repair because of the prompt growth of gingival epithelium. Nyman et al. ${ }^{9}$ and Stahl et al. ${ }^{10}$ have shown that the use of GTR barriers excludes the epithelial and gingival connective from the periodontal wound healing process, so as to attain regeneration of the attachment apparatus. 
On the one hand, the non-absorbable d-PTFE membrane that has been used in this trial has certain integral advantages over the absorbable membrane. It provides the clinician with superior control over the length of time as the membrane stays in place. ${ }^{11}$ In general, the short coming of the non-absorbable membrane is the requirement of second surgery for membrane removal. On the other hand, d-PTFE is thick in form and does not mechanically lock into the healing connective tissue, and, thus, can be removed by engaging the edge of the membrane.

In addition to providing osteoinductive/osteoconductive capacity for regeneration, bone grafts also maintain the space. Khanna et al. ${ }^{12}$ demonstrated better results when bone grafts were combined with the GTR membrane in the treatment of grade II furcation defects, yielded in comparison with the open flap debridement procedure. Similar results were established by Prathap et al. ${ }^{13}$ who demonstrated the combination of GTR and bone grafts to be more efficacious than bone grafts alone in the management of grade II furcation.

During the treatment of furcation defect, the direct measurement of horizontal attachment loss in the furcation (horizontal bone fill) during surgical reentry is considered the primary response variable. In this study, a statistically significant improvement of horizontal bone fill was found in all the three groups. Intergroup comparisons revealed a significant change in all groups ( $p=0.001)$. These findings are in comparison with the results obtained by Pal et al., ${ }^{14}$ Yukna and Yukna, ${ }^{15}$ and Blumenthal ${ }^{16}$ who used a collagen membrane.

In this study, a significant reduction in probing depth, starting baseline to 6 months postoperatively, was found. This was in agreement with the findings of De Leonardis et al. ${ }^{17}$ and Tsao et al. ${ }^{18}$ who demonstrated a significant difference in vertical bone fill in the control group and test groups at 6 months.

Healiguide, an absorbable collagen membrane, has been newly developed, particularly for periodontal regeneration. With Healiguide, the need for a donor site is eliminated and it provides limitless material availability. It does not induce immune response and can, thus, be used safely in humans. When used in the treatment of gingival recession defects, it aids in periodontal regeneration. In contrast to other nonabsorbable barriers, Healiguide does not require surgical removal, as it steadily integrates with the host tissue. In the present trial, better improvement has been recorded in the treatment of grade II infrabony defects with the use of bioabsorbable Healiguide. Sometimes, there could be a barrier membrane contamination threat with the use of GTR, which may either be due to exposure to the oral environment or to the infection-prone healing wound. The barrier material establishes an ecological habitat that is appropriate for the growth of, and colonization by, the purported periodontopathic organisms, which is attributable to its structural and textural characteristics. This decreases the gain in the clinical attachment achieved with surgery and also stops the organization and amalgamation with the connective tissue. ${ }^{19}$

An effective prevention and treatment of periodontitis relies upon active control of the dwelling microorganisms by mechanical therapy combined with local or systemic antimicrobial treatment. ${ }^{20}$

The shortcomings of the present study were smaller sample size, lack of any histological confirmation on the procedure-based healing of the flap and the collagen membrane, and absence of radiographic assessment.

\section{Conclusion}

The present study reported that both membranes result in clinically and statistically significant improvements in the treatment of grade II furcation defects, and this suggests that the success of the GTR procedure is not only limited to the type of membrane material used, but also related to many extrinsic factors, such as membrane handling features, simple placement procedure, biological acceptance, furcation defect morphology, and plaque control. However, with regard to horizontal bone fill, the bioabsorbable barrier membrane showed better results.

\section{Clinical Significance}

GTR is used to regenerate lost periodontal structures, such as cementum, periodontal ligament, and alveolar bone by means of selective cell and tissue renewal of the periodontal wound. The GTR procedure aids to limit or permit the repopulation of periodontal defects and the neighboring root surfaces by cells from surrounding tissue sources.

\section{References}

1. Zucchelli G, Bernardi F, et al. Enamel matrix proteins and guided tissue regeneration with titanium-reinforced expanded polytetrafluoroethylene membranes in the treatment of infrabony defects: a comparative controlled clinical trial. J Periodontol 2002;73(1):3-12. DOI: 10.1902/jop.2002.73.1.3.

2. Wadhawan A, Gowda TM, et al. Gore-tex ${ }^{\circledR}$ versus resolut adapt ${ }^{\circledR}$ GTR membranes with perioglas ${ }^{\circledR}$ in periodontal regeneration. Contemp Clin Dent 2012;3:406-411. DOI: 10.4103/0976-237X.107427.

3. Nyman S, Gottlow J, et al. The regenerative potential of the periodontal ligament. J Clin Periodontol 1982;9:257-265.

4. Chaturvedi R, Gill AS, et al. Evaluation of the regenerative potential of $25 \%$ doxycycline-loaded biodegradable membrane vs biodegradable membrane alone in the treatment of human periodontal infrabony defects: a clinical and radiological study. Indian J Dent Res 2008;19:116-123.

5. Mengel R, Soffner M, et al. Bioabsorbable membrane and bioactive glass in the treatment of intrabony defects in patients with generalized aggressive periodontitis-results of a 12 month clinical and radiological study. J Periodontol 2003;74(6):899-908.

6. Pretzl B, Kim TS, et al. Guided tissue regeneration with bioabsorbable barriers. III 10 years results in infrabony defects. J Clin Periodontol 2009;36(4):349-356. DOI: 10.1111/j.1600-051X.2009.01378.x.

7. Loe $H$, Anerud A, et al. The natural history of periodontal disease in man: prevalence, severity, and extent of gingival recession. J Periodontol 1992;63:489-495.

8. Wennstrom JL. Mucogingival Therapy. Ann Periodontol 1996;1:671701.

9. Nyman S, Lindhe J, et al. New attachment following surgical treatment of human periodontal disease. J Clin Periodontol 1982;9(4):290-296.

10. Stahl SS, Froum S, et al. Human histologic responses to guided tissue regenerative techniques in intrabony lesions. Case reports on 9 sites. J Clin Periodontol 1990;17(3):191-198.

11. Stephen PW, Greenwell H, et al. Comparison of porous and nonporous Teflon membrane plus a xenograft in the treatment of vertical osseous defects. A clinical re-entry study. J Periodotol 2003;74(8):1161-1168.

12. Khanna D, Malhotra S, et al. Treatment of Grade II furcation involvement using resorbable guided tissue regeneration membrane: a six-month study. J Indian Soc Periodontol 2012;16:404-410. DOI: 10.4103/0972-124X.100920.

13. Prathap S, Hegde $S$, et al. Clinical evaluation of porous hydroxyapatite bone graft (Periobone $\mathrm{G}$ ) with and without collagen membrane (Periocol) in the treatment of bilateral grade II furcation defects 
in mandibular first permanent molars. J Indian Soc Periodontol 2013;17:228-234. DOI: 10.4103/0972-124X.113083.

14. Pal TK, Mahajan A, et al. Clinical evaluation of collagen chitosan as a barrier membrane in the treatment of periodontal osseous defects. JISP 2003;36-45.

15. Yukna CN, Yukna RA. Multi-center evaluation of bioabsorbable collagen membrane for guided tissue regeneration in human class II furcation. J Periodontol 1996;67:650-657. DOI: 10.1902/jop.1996.67.7.650

16. Blumenthal NM. A clinical comparison of collagen membranes with e-PTFE membranes in the treatment of human mandibular buccal class II furcation defects. J Periodontol 1993;64:925-933. DOI: 10.1902/ jop.1993.64.10.925
17. De Leonardis D, Garg AK, et al. Clinical evaluation of the treatment of class II furcation involvements with bioabsorbable barriers alone or associated with demineralized freeze-dried bone allografts. J Periodontol 1999;70:8-12. DOI: 10.1902/jop.1999.70.1.8.

18. Tsao YP, Neiva R, et al. Effects of a mineralized human cancellous bone allograft in regeneration of mandibular class II furcation defects. J Periodontol 2006;77:416-425. DOI: 10.1902/jop.2006.050109.

19. Ling $L J$, Hung $S L$, et al. The influence of membrane exposure on the outcomes of guided tissue regeneration: clinical and microbiological aspects. J Periodontal Res 2003;38:57-63.

20. Mombelli A, Samaranayake LP. Topical and systemic antibiotics in the management of periodontal diseases. Int Dent J 2004;54:3-14. 